\title{
Screening for Temporomandibular Disorders and Other Oral Conditions among Adolescents in Mangaluru Taluk
}

\author{
Rekha P Shenoy ${ }^{1}$, Reema Agrawal ${ }^{2}$, TA Abdul Salam ${ }^{3}$, K Prashanth Shenoy $^{4}$
}

\begin{abstract}
Aim: While dental caries and periodontal disease are the most prominent oral diseases, other oral conditions have not been adequately investigated. This study was undertaken to assess and compare prevalence of extraoral and oral mucosal lesions, temporomandibular disorders (TMDs), and traumatic dental injuries among children enrolled in high schools in Mangaluru taluk.

Materials and methods: A cross-sectional study was carried out among 1,340 children selected through stratified cluster sampling from government and private high schools in urban and rural areas. A pro forma was prepared to record demographic data, and oral findings according to the World Health Organization criteria. Data were analyzed using Chi-squared test and $t$-test with a $p$ value of less than 0.05 considered statistically significant.

Results: Prevalence of extraoral lesions was found to be $0.2 \%$. The prevalence of TMD symptoms and TMD signs was $2.4 \%$ and $2.5 \%$, respectively. The presence of TMD symptoms and TMD signs was significantly higher among females, children belonging to rural areas, and among private schoolchildren. The oral lesions found were traumatic ulcerations (in $0.8 \%$ study participants), the majority of which affected children attending urban schools. The prevalence of traumatic dental injuries was $6.7 \%$, and it was significantly higher among males. Maxillary incisors were the most affected teeth.

Conclusion: Although the prevalence of the oral conditions was low, their presence indicates a need for early identification of those affected so that the treatment can be expedited and the severity of the condition can be limited.

Clinical significance: Data on prevalence and severity recorded according to standardized criteria are a prerequisite for effective interception of oral conditions such as oral mucosal lesions, TMDs, and dentofacial injuries. This survey will provide data on children from diverse socioeconomic backgrounds and facilitate prioritizing of treatment services to the most deserving.

Keywords: Dental trauma, Oral lesions, Schoolchildren, Temporomandibular disorders.

World Journal of Dentistry (2020): 10.5005/jp-journals-10015-1728
\end{abstract}

\section{INTRODUCTION}

Oral diseases are major public health problems due to high prevalence and significant social impact. ${ }^{1,2}$ They cause pain, interfere with normal function and social interaction, and increase the financial burden on the afflicted, thereby influencing the quality of life. ${ }^{1-3}$ Therefore, healthy oral tissues are prerequisite for the physical, social, and psychological development of a child. ${ }^{3}$ Developing countries like India face many challenges in rendering oral health needs such as lack of awareness about dental diseases, low educational levels, lack of beliefs and culture in support of oral health, and a large rural population. ${ }^{1,2}$

While dental caries and periodontal disease are the most prominent and researched oral diseases, there are other conditions such as extraoral lesions, TMDs, oral mucosal lesions, and traumatic dental injuries which need to be adequately investigated. Extraoral lesions in the head and neck region present such as ulcerations, sores, erosions, fissures, abnormalities of the lips, enlarged lymph nodes. ${ }^{4} \mathrm{~A}$ search of literature revealed a paucity of data on the prevalence of extraoral lesions among adolescents.

Temporomandibular disorders (TMDs) is a collective term for disorders characterized by pain in the temporomandibular joint (TMJ) and the muscles of mastication, restricted mandibular movement, and the presence of articular clicking. Their occurrence is attributed to emotional stress, malposition or loss of teeth, muscle dysfunction, etc. TMDs are the main causes of non-dental or facial pain and are diagnosed by associating signs and symptoms. ${ }^{5,6}$ Very little documentation exists on their prevalence among adolescents,
${ }^{1}$ Department of Public Health Dentistry, Yenepoya Dental College, Mangaluru, Karnataka, India

${ }^{2}$ Department of Public Health Dentistry, Manubhai Vishwajyoti Ashram, Vadodara, Gujarat, India

${ }^{3}$ Department of Public Health Dentistry, PMS College of Dental Science and Research, Vattappara, Kerala, India

${ }^{4}$ Department of Oral Medicine and Radiology, Yenepoya Dental College, Mangaluru, Karnataka, India

Corresponding Author: Rekha P Shenoy, Department of Public Health Dentistry, Yenepoya Dental College, Mangaluru, Karnataka, India, Phone: +91 98451 32999, e-mail: merekhap@yahoo.co.in

How to cite this article: Shenoy RP, Agrawal R, Abdul Salam TA, et al. Screening for Temporomandibular Disorders and Other Oral Conditions among Adolescents in Mangaluru Taluk. World J Dent 2020;11(3):201-205.

Source of support: Nil

Conflict of interest: None

which is necessary to formulate effective strategies to prevent the progress of TMDs into adulthood.

The oral mucous membrane is looked upon as a mirror of general health. Oral mucosal lesions may be present at birth or become evident in later life. They are usually discovered during routine dental examinations and may reflect underlying systemic conditions. They present with varying prevalence depending on age, gender, race, or geographic location., ${ }^{7,8}$ There are very few 
studies documenting the prevalence of mucosal lesions among adolescents in the Indian subcontinent, and no studies in Mangaluru taluk. This lack of data is a critical deficiency and may lead to overlooking of diseases of the oral soft tissues.

Traumatic dental injuries occur frequently during adolescence and result from sports or road accidents, violence, or accidental falls. ${ }^{1,2}$ The face and anterior teeth have a high tendency to be traumatized. ${ }^{9}$ Traumatic injuries can cause extensive loss of tooth structure and may have a great psychological impact on the child, restricting oral function and affecting esthetics. ${ }^{10,11}$ There is a lack of recent data on the prevalence of traumatic dental injuries among high school-going children in this region.

Government schools are funded and managed by the government, while private schools are privately managed and funded. The school a child attends is often determined by parents' socioeconomic status. Thus, the type of school can be considered a surrogate or proxy indicator for socioeconomic status and can facilitate epidemiological surveys of oral health by simplifying data collection. ${ }^{12,13}$

Effective interception of TMDs and dentofacial injuries and early treatment of extraoral and oral mucosal lesions require the documentation of their prevalence and severity in the target population to help identify treatment needs. This survey was necessitated by the fact that these oral parameters had not been evaluated in this population cohort or in this region according to the World Health Organization criteria. ${ }^{4}$ The present study was undertaken to assess and compare the prevalence of extraoral and oral mucosal lesions, TMDs, and traumatic dental injuries among children enrolled in government and private high schools in urban and rural areas of Mangaluru taluk.

\section{Materials and Methods}

This cross-sectional study was carried out from January 2013 to March 2015. Spread over 834 square kilometers, Mangaluru taluk has a population of approximately 882,856 , with urban areas accounting for $68.1 \%$ of the population. ${ }^{14}$

Schools in Mangaluru taluk are allotted to two divisions, Mangaluru City and Mangaluru Rural. The permission to carry out the study and the list of high schools in the taluk were obtained from Block Educational Officers of both divisions. High schools in the taluk numbered 191 and consisted of 100 government and 91 private schools; 70 were urban-based and 121 were located in rural areas. The sample size was determined to be $1340 .{ }^{15}$

After obtaining Ethical Clearance (Reference Number YUEC/89/11/8/12), stratified cluster sampling was used to select government and private high schools in urban and rural areas. As data on the number of children in each school were unavailable, 670 children each were examined from ten randomly selected schools in urban and rural areas, respectively (i.e., 335 children each from government and private schools). School authorities were contacted to obtain permission. In these schools, all students who fulfilled the inclusion criteria-studying from 8th to 10th standards, present on the day of the survey and consenting to participatewere examined till the required sample was obtained.

A pro forma was used to record demographic data, and findings of the extraoral examination, temporomandibular assessment, oral mucosal assessment, and the presence of traumatic dental injuries. ${ }^{4}$ Demographic data recorded included name, age, gender, type of school and location, and date of examination. During the extraoral examination, the head and neck region would be examined for the presence of ulcerations, sores, erosions, fissures, swellings, abnormalities of upper and lower lips, and enlarged lymph nodes. Temporomandibular assessment would include eliciting symptoms such as clicking, pain or difficulty in opening and closing the mouth, and checking for signs such as clicking, tenderness on palpation, and reduced jaw mobility ( $<30 \mathrm{~mm}$ opening). Oral soft tissues such as the vermilion border, commissures, lips, sulci, buccal mucosa, floor of the mouth, tongue, hard and soft palate, and alveolar ridges were to be examined for dysplastic changes, ulcerations, acute necrotizing gingivitis, abscess, and candidiasis. The dentition was evaluated for loss of tooth structure due to trauma with no evidence of dental caries.

Prior to starting the study, the investigator was trained and the $\mathrm{K}$ statistic was found to be 0.84 . The investigator was calibrated a total of three times during the study period, and the intra-examiner reliability was found to range from 0.80 to 0.84 . Two recording clerks assisted during the data collection exercise, and standard precautions were followed throughout. Before starting the survey, parental informed consent and written assent of the participants was obtained. Oral examinations were performed under adequate natural light in the school premises.

\section{Statistical Analysis}

Data were entered into the Statistical Package for the Social Sciences (SPSS) version 20.0 and analyzed using Chi-squared $\left(\chi^{2}\right)$ test and $t$-test. A $p$ value of less than 0.05 was considered statistically significant.

\section{Results}

The study population comprised of 773 boys and 567 girls (total 1340 ), in the age range from 11 to 18 years. A majority ( $80.6 \%$ boys and $81.3 \%$ girls) were in the 13-15-year age group.

\section{Extraoral Lesions}

Only two children presented with extraoral lesions-one urban female from a private school with upper lip abnormality and one rural male from a government school with ulceration at lip commissure. The overall prevalence was $0.2 \%$. Inferential statistics were not done for this variable as there were only two cases.

\section{Temporomandibular Joint Assessment}

$0.8 \%$ urban and $4.0 \%$ rural children, and $0.9 \%$ students from government and $3.9 \%$ students from private schools reported TMJ symptoms (overall prevalence $2.4 \%$ ) (Table 1). The prevalence was significantly higher among female participants $\left(\chi^{2}=7.30 ; p=0.007\right)$. The prevalence of TMJ symptoms was five times higher among rural $\left(\chi^{2}=15.50 ; p<0.001\right)$ and almost four times higher among private schoolchildren $\left(\chi^{2}=12.81 ; p<0.001\right)$.

Clinical examination revealed that $1.0 \%$ urban and $4.0 \%$ rural, and $1.0 \%$ from government and $4.0 \%$ private schoolchildren manifested TMJ signs such as clicking, tenderness, and reduced jaw mobility (overall prevalence $2.5 \%$ ). Significantly, higher prevalence was seen among females $\left(\chi^{2}=7.30 ; p=0.007\right)$, with the majority of the affected children belonging to rural $\left(\chi^{2}=10.37 ; p=0.001\right)$ and private schools $\left(\chi^{2}=12.81 ; p<0.001\right)$.

\section{Oral Mucosal Lesions}

Traumatic ulcerations were the only oral lesions found in the study participants. Ten children presented with ulcerations located in the following areas-six on the buccal mucosa, three on the lips, 
Table 1: Distribution of participants according to the prevalence of TMDs, oral mucosal lesions, and traumatic dental injuries

\begin{tabular}{lclll}
\hline & $\begin{array}{l}\text { Urban } \\
\text { schools }\end{array}$ & $\begin{array}{l}\text { Rural } \\
\text { schools }\end{array}$ & $\begin{array}{l}\text { Government } \\
\text { schools }\end{array}$ & $\begin{array}{l}\text { Private } \\
\text { schools }\end{array}$ \\
\hline $\begin{array}{l}\text { Temporomandibular disorders } \\
\quad \text { Symptoms }\end{array}$ & $05(0.8 \%)$ & $27(4.0 \%)$ & $06(0.9 \%)$ & $26(3.9 \%)$ \\
$\quad$ Signs & $07(1.0 \%)$ & $27(4.0 \%)$ & $07(1.0 \%)$ & $27(4.0 \%)$ \\
$\begin{array}{l}\text { Oral mucosal lesions } \\
\quad \text { Presence of } \\
\text { traumatic } \\
\text { ulcerations }\end{array}$ & $09(1.3 \%)$ & $01(0.2 \%)$ & $04(0.6 \%)$ & $06(0.9 \%)$ \\
$\begin{array}{l}\text { Traumatic dental injuries } \\
\text { Injuries involving }\end{array}$ & $41(6.1 \%)$ & $49(7.3 \%)$ & $45(6.7 \%)$ & $45(6.7 \%)$ \\
\begin{tabular}{l}
1 or 2 teeth \\
\hline
\end{tabular} & & & & \\
\hline
\end{tabular}

and one at the lip commissure. Nine of the 10 affected children attended urban schools $\left(\chi^{2}=6.45 ; p=0.011\right.$ ) (Table 1). Differences based on the gender and category of the school were not significant $(p>0.05)$.

\section{Traumatic Dental Injuries}

The prevalence of traumatic injuries was $6.7 \%$. Injuries to maxillary and mandibular anterior teeth were present in $6.1 \%$ urban and $7.3 \%$ rural participants, and among $6.7 \%$ students from both government and private schools (Table 1). Single tooth injuries were seen in $88.9 \%$ cases while $11.1 \%$ showed involvement of two teeth. Maxillary central incisors were most affected (79.0\%), followed by maxillary lateral incisors (15.0\%) and mandibular central incisors (4.0\%). The prevalence was significantly higher among males ( $p$ $=0.002$ ). However, it did not differ according to the location or category of the school.

The inference of the study was that among children enrolled in government and private high schools in urban and rural areas of Mangaluru taluk, the prevalence of extraoral lesions and oral mucosal lesions was $0.2 \%$ and $0.8 \%$, respectively. The TMJ assessment showed $2.4 \%$ children reporting TMJ symptoms and $2.5 \%$ presenting with TMJ signs. The prevalence of traumatic dental injuries was $6.7 \%$.

\section{Discussion}

The mean age of 1340 participants was $13.91 \pm 1.17$ years, and males numbered more than females. While the present study found only two participants with extraoral lesions, a survey carried out in Mysore district, India, by Havaldar et al. found $2.7 \%$ adolescents with extraoral lesions of which $2.3 \%$ were extraoral ulcerations. ${ }^{16}$

No literature exists on the prevalence of TMD symptoms and signs among adolescents in Mangaluru taluk. The prevalence of TMD symptoms among urban children in this study was $0.4 \%$, much lower than reported by Feteih RM among urban Saudi Arabian adolescents (33.0\%). ${ }^{5}$ The prevalence of TMD symptoms was significantly higher among females. ${ }^{5}$ The TMD signs such as clicking, tenderness, and reduced jaw mobility were found in $2.5 \%$ participants, lower than found in Mexican $(26.1 \%)^{17}$ and Saudi Arabian $(21.3 \%)^{5}$ adolescents but similar to that reported by Chauhan et al. ${ }^{6}$ (2.5\%) in schoolchildren from Himachal Pradesh. Higher prevalence among females was mirrored in studies conducted among Caucasian, ${ }^{18}$ Saudi Arabian, ${ }^{5}$ and Himachal Pradesh ${ }^{6}$ adolescents. Higher prevalence of TMD signs among females may be attributed to lower pain threshold, stress, and hormonal changes. ${ }^{5,6,17,18}$ A survey of Himachal Pradesh schoolchildren by Chauhan et al. ${ }^{6}$ found that children belonging to urban background were more affected, which contrasted with our findings. Orthodontic treatment can be used to treat certain TMD patients after a thorough investigation of the etiology. ${ }^{17}$ Therefore, routine dental examination in adolescents should include evaluation of the TMJ and related musculature. No literature is available on the differences in the prevalence of TMD symptoms and signs among government and private schoolchildren.

This is the first epidemiological study in Mangaluru taluk evaluating the prevalence of oral mucosal lesions among adolescents. The only oral lesion found in this study population was traumatic oral ulcer. The prevalence of traumatic oral ulcerations was $0.8 \%$, which was lower than reported among adolescents from Manipal (1.7\%), ${ }^{8}$ the United States (9.1\%), ${ }^{19}$ and Tehran (28.0\%). ${ }^{7}$ No significant differences were observed between genders; ${ }^{20}$ however, a higher prevalence among males has been reported by Shulman among American youth. ${ }^{19}$ Majority of the affected children were from urban areas, which has also been reported by Kumari et al. among schoolchildren in Lucknow. ${ }^{20}$ Traumatic ulcerations, which are the most commonly found ulcerations, are caused by physical/ mechanical, thermal, or chemical trauma. In the present study, traumatic ulcerations were located on the buccal mucosa and lips. Similar findings have been reported among adolescents in the United States by Shulman. ${ }^{19}$

The prevalence of traumatic injuries (6.7\%) was lower than reported in Iran (27.6\%), ${ }^{21}$ the Middle East (5.0-12.0\%), ${ }^{1}$ Latin America (15.0\%), ${ }^{1}$ Sweden (35.0\%), ${ }^{22}$ and Tamil Nadu (10.1\%). ${ }^{10}$ In a majority of cases, traumatic injuries affected single teeth. ${ }^{10}$ The most affected teeth were maxillary incisors, followed by mandibular incisors. ${ }^{10,21}$ High prevalence among boys can be explained by their greater inclination towards vigorous activities. ${ }^{10,21,22}$

There was a lack of scientific literature on comparison in the prevalence of extraoral lesions, oral mucosal lesions, and traumatic dental injuries among government-private schoolchildren, and among urban-rural adolescents. This study was carried out to fill these lacunae. The present study was limited to school-going children, and therefore, the findings cannot be generalized to all children of this age range. Primary prevention of oral disease is the ultimate goal of preventive dentistry. Early identification of those with extraoral and oral mucosal lesions can expedite treatment so that the severity of the condition is limited. Screening programs at schools can help identify those at risk of traumatic injuries and TMDs, so that the appropriate measures such as the use of mouth guards and orthodontic treatment can be implemented. Educating the community, and, in specific, schoolchildren, and teachers on the methods of preventing dental injuries and the need for immediate treatment of fractured teeth can reduce the severity of the trauma. This study, carried out using the standardized criteria, will provide baseline data that will enable comparison with the future studies.

\section{Conclusion}

The prevalence of extraoral and oral mucosal lesions, TMDs, and traumatic dental injuries which were evaluated in this study among children enrolled in government and private high schools in urban and rural areas of Mangaluru taluk was low. However, their presence indicates a need for early identification of the affected children so that the treatment can be delivered at the earliest and the severity of the condition can be minimized. 


\section{Clinical Significance}

Data on prevalence and severity recorded according to the standardized criteria (of the World Health Organization) are a prerequisite for effective interception of oral conditions such as oral mucosal lesions, TMDs, and dentofacial injuries. This survey will provide data on children from diverse socioeconomic backgrounds and facilitate prioritizing of treatment services to the most deserving, especially when resources are sparse.

\section{References}

1. Petersen PE. Challenges to improvement of oral health in the 21st century - the approach of the WHO global oral health programme. Int Dent J 2004;54(S6):329-343. DOI: 10.1111/j.1875-595x.2004.tb00009.x.

2. Petersen PE. Improvement of oral health in Africa in the 21st century - the role of the WHO global oral health programme. Afr J Oral Health 2004;1(1):2-16. DOI: 10.4314/ajoh.v1i1.31299.

3. Ingle NA, Dubey HV, Kaur N, et al. Prevalence of dental caries among school children of Bharatpur city, India. J Int Soc Prev Community Dent 2014;4(1):52-55. DOI: 10.4103/2231-0762.131267.

4. World Health Organization. Oral Health Surveys: Basic Methods. 4th ed., Geneva: World Health Organization; 1997. p. 22-44.

5. Feteih RM. Signs and symptoms of temporomandibular disorders and oral parafunctions in urban Saudi Arabian adolescents: a research report. Head Face Med 2006;2(1):25. DOI: 10.1186/1746-160X-2-25.

6. Chauhan D, Kaundal J, Karol S, et al. Prevalence of signs and symptoms of temporomandibular disorders in urban and rural children of northern hilly state, Himachal Pradesh, India: a cross sectional survey. Dent Hypotheses 2013;4(1):21-25. DOI: 10.4103/2155-8213.110182.

7. Jahanbani J, Morse $\mathrm{DE}$, Alinejad $\mathrm{H}$. Prevalence of oral lesions and normal variants of the oral mucosa in 12 to 15 -year-old students in Tehran, Iran. Arch Iran Med 2012;15(3):142-145. DOI: 012153/AIM.007.

8. Mathew AL, Pai KM, Sholapurkar AA, et al. The prevalence of oral mucosal lesions in patients visiting a dental school in Southern India. Indian J Dent Res 2008;19(2):99-103. DOI: 10.4103/0970-9290.40461.

9. Gupta K, Tandon S, Prabhu D. Traumatic injuries to the incisors in children of South Kanara district. A prevalence study. J Indian Soc Pedod Prev Dent 2002;20(3):107-113.

10. Govindarajan M, Reddy VN, Ramalingam K, et al. Prevalence of traumatic dental Injuries to the anterior teeth among three to thirteen-year-old school children of Tamil Nadu. Contemp Clin Dent 2012;3(2):164-167. DOI: 10.4103/0976-237X.96819.

11. Ravishankar TL, Kumar MA, Ramesh N, et al. Prevalence of traumatic dental Injuries to permanent incisors among 12-year-old school children in Davangere, South India. Chin J Dent Res 2010;13(1):57-60.

12. Goyal S, Pandey P. Report No. 30. South Asia Human Development Sector. How do government and private schools differ? Findings from two large Indian states. Discussion paper. December 2009. Available from: http://datatopics.worldbank.org/hnp/files/edstats/INDwp09b. pdf [Accessed 8th January 2015].

13. Kingdon $G$. The quality and efficiency of private and public education: a case-study of urban India. Oxf Bull Econ Stat 1996;58(1):57-82. DOI: 10.1111/j.1468-0084.1996.mp58001004.x.

14. Government of Karnataka, 2001. Census of India 2001. Available from: http://www.karnatakaindustry.gov.in [Accessed 12th May 2014].

15. Dental Council of India. National Oral Health Survey \& Fluoride Mapping 2002-2003 Karnataka. New Delhi: Dental Council of India and Ministry of Health \& Family Welfare, Government of India; 2004.

16. Havaldar KS, Bhat SS, Hegde SK. Oral health status of Tibetan and local school children of Kushalnagar, Mysore district, India: a comparative study. J Indian Soc Pedod Prev Dent 2014;32(2):125-129. DOI: 10.4103/0970-4388.130959.

17. Sanchez-Perez L, Irigoyen-Camacho M, Molina-Frechero N, et al. Malocclusion and TMJ disorders in teenagers from private and public schools in Mexico city. Med Oral Patol Oral Cir Bucal 2013;18(2):e312e318. DOI: 10.4317/medoral.18075.

18. Tecco S, Crincoli V, Di Bisceglie B. Signs and symptoms of temporomandibular joint disorders in Caucasian children and adolescents. Cranio 2011;29(1):71-79. DOI: 10.1179/crn.2011.010.

19. Shulman JD. Prevalence of oral mucosal lesions in children and youths in the USA. Int J Paediatr Dent 2005;15(2):89-97. DOI: 10.1111/j.1365263X.2005.00632.x.

20. Kumari M, Reddy LVK, Mohd S, et al. Oral mucosal lesions among 12and 15-year-old school going children of Lucknow district - A cross sectional survey. Int J Dent Sci Res 2013;1(1):16-19. DOI: 10.1016/j. ijdsr.2013.03.001.

21. Navabazam A, Farahani SS. Prevalence of traumatic injuries to maxillary permanent teeth in 9- to 14-year-old school children in Yazd, Iran. Dent Traumatol 2010;26(2):154-157. DOI: 10.1111/j.16009657.2009.00861.x.

22. Borssén E, Holm AK. Traumatic dental injuries in a cohort of 16-yearolds in northern Sweden. Endod Dent Traumatol 1997;13(6):276-280. DOI: 10.1111/j.1600-9657.1997.tb00055.x. 
Name:

Age:__years

Gender: Male/Female

Type of school: Government/Private

Location of school: Urban/Rural

Date of examination:

Extraoral examination of the head and neck region:

Normal $=0$

Ulcerations $=1$

Sores $=2$

Erosions $=3$

Fissures $=4$

Swellings $=5$

Abnormalities of upper and lower lips $=6$

Enlarged lymph nodes $=7$

Temporomandibular joint assessment:

Symptoms

No symptoms $=0$

Clicking $=1$

Pain $=2$

Difficulty in opening and closing the mouth $=3$

\section{Signs}

No signs $=0$

Clicking $=1$

Tenderness on palpation $=2$

Reduced jaw mobility ( $<30 \mathrm{~mm}$ opening $)=3$

Oral mucosa:

Condition

No abnormality $=0$

Dysplastic changes $=1$

Ulcerations $=2$

Acute necrotizing gingivitis $=3$

Abscess $=4$

Candidiasis $=5$

Location

Vermilion border $=1$

Commissures $=2$

Lips $=3$

Sulci $=4$

Buccal mucosa $=5$

Floor of the mouth $=6$

Tongue $=7$

Hard and soft palate $=8 \mathrm{a}$

Alveolar ridges $=8 \mathrm{~b}$

\section{Traumatic dental injuries $(\mathrm{T})$ :}

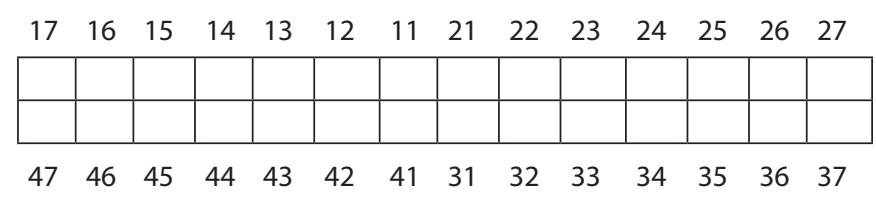

